\title{
Particle flow and segregation in a giant landslide event triggered by the 2008 Wenchuan earthquake, Sichuan, China
}

\author{
L. M. Zhang ${ }^{1,2}$, Y. Xu ${ }^{1,3}$, R. Q. Huang ${ }^{2}$, and D. S. Chang ${ }^{1}$ \\ ${ }^{1}$ Department of Civil and Environmental Engineering, The Hong Kong University of Science and Technology, \\ Clear Water Bay, Hong Kong, China \\ ${ }^{2}$ State Key Laboratory of Geohazard Prevention and Geoenvironment Protection, Chengdu University of Technology, \\ Chengdu, Sichuan, China \\ ${ }^{3}$ China Institute of Water Resources and Hydropower Research, Beijing, China
}

Received: 27 July 2010 - Accepted: 28 March 2011 - Published: 26 April 2011

\begin{abstract}
During the 12 May 2008 Wenchuan earthquake, a large landslide of approximately 30 million $\mathrm{m}^{3}$ occurred at Donghekou with a particle run-out distance of over $2000 \mathrm{~m}$. This paper presents fascinating particle flow and segregation characteristics in the landslide process found through field investigation of changes in the soil particle size, density, and fabric along the particle movement paths. The soil particles experienced projection, long-distance flying, sliding, and rolling. Trajectory segregation, inverse grading, and particle crushing were found in the landslide event, which contributed to the heterogeneity of the soil deposits. In the initial deposition area, particles with larger diameters appeared to have flown longer. Materials from different sources mixed, forming more uniform debris. In the run-out area, the particle flow tended to cause large particles to travel further. However, particle disintegration and crushing led to more small particles along the movement paths and the observed characteristic flow distances of very large particles did not increase with the particle diameter, which is different from observations of an idealized granular mass flow.
\end{abstract}

\section{Introduction}

On 12 May 2008, an earthquake of magnitude 8.0 centred in Wenchuan occurred in Sichuan, China (Huang, 2008; Xie et al., 2008; Cui et al., 2009; Wang et al., 2009; Yin et al., 2009; Chang and Zhang, 2010). This earthquake triggered approximately 30000 landslides, which caused approximately 20000 fatalities (Sato and Harp, 2009; Zhang, 2009). In managing the risks imposed by large landsides, engineer face

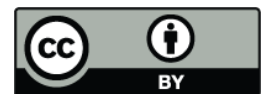

Correspondence to: L. M. Zhang (cezhangl@ust.hk) a tremendous number of uncertainties regarding geological features as well as heterogeneity in the fabric, structure, and properties of landslide deposits (Costa and Schuster, 1988; Schuster et al., 1992; Lacasse et al., 2004; Tang et al., 2006; Wang and Sassa, 2009). Particle segregation or sorting occurring in the particle flow process of a landslide is a major mechanism for such heterogeneity. It is important to understand the mechanism leading to particle segregation and to characterize the heterogeneity in-situ.

Processes such as pouring, shaking, vibration, shearing, fluidization, and freezing and thawing can lead to particle sorting (Jullien and Meakin, 1990). Grain size sorting inevitably occurs in granular mass flows and it enhances the development of nonuniform surge fronts. Commonly, flows selectively sort large grains upward and small grains downward (Iverson and Vallance, 2001). In other words, large particles move to the front and to the top surface whilst small particles accumulate at the bottom and in the rear part of the flow deposits (Wang and Hutter, 2001). As grain size segregation produces concentrations of large grains at the debris surface, where the velocities are typically the fastest, large grains preferentially migrate to the surge fronts. In the case of a growing heap on an infinite planar surface or within a cylinder of finite radius, the large particles are concentrated onto the lower and outer parts of the heap whereas the small particles are concentrated onto the upper part of the heap and in its core. The degree of segregation reflects both the grain size and the number of particles (Jullien and Meakin, 1990).

The mechanism of particle segregation is very complex due to many influencing factors involved, i.e. particle size, density, shape, resilience, etc (Williams, 1976). A number of laboratory experiments have been carried out to better understand the process of particle flow and segregation (e.g. Davies, 1986, 1988; Savage and Lun, 1988; Dolgunin and Ukolov, 1995; Vallance and Savage, 2000; Zhou, 2010). On

Published by Copernicus Publications on behalf of the European Geosciences Union. 


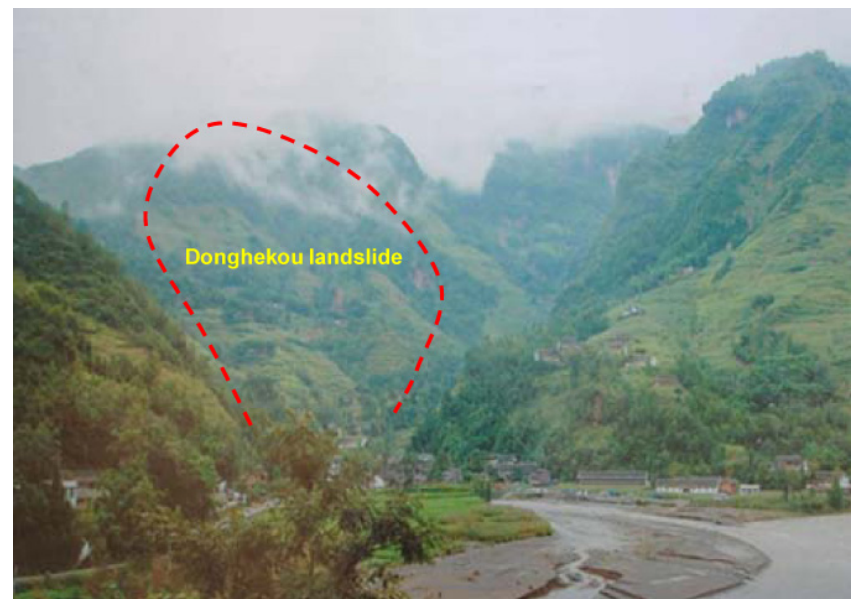

Fig. 1. Overview of the area of Donghekou before the 2008 Wenchuan earthquake.

the other hand, many analytical and numerical models have been developed to simulate the process of particle segregation (e.g. Savage and Lun, 1988; Jullien and Meakin, 1990; Anderson and Bunas, 1993; Khakhar et al., 1999; Gray and Thornton, 2005; Thornton et al., 2006; Thornton and Gray, 2008). Laboratory experiments and theoretical studies often encounter scale effects and/or simplifications that may make outcomes from such studies not readily comparable to real-life particle flow and segregation situations. Full-scale field investigations, of which limited information is currently available, are inevitably one of the most important steps to understand the complex natural phenomena and validate theoretical models.

The primary objective of this paper is to collect evidence and investigate characteristics of particle flow and segregation occurring in a large-scale landslide process. In this study, we conducted a field investigation on a giant fresh deposit of the Donghekou landslide, which was triggered by the Wenchuan earthquake. The field investigation was conducted before the originally fresh soil deposit was disturbed. The geological and topographic environment of the Donghekou landslide as well as the landslide itself are first introduced. Then, the characteristics of particle flows in the landslide process, particularly particle segregation, are studied through detailed field surveys of changes in soil particle sizes, density, and fabric along the mass movement paths. A comparison between the real and the ideal granular mass flows is also conducted to give a full view of the possible mechanisms involved in a landslide event. This paper, however, does not intend to investigate the failure mechanisms of the landslide or shear strength behaviour of the landslide debris.
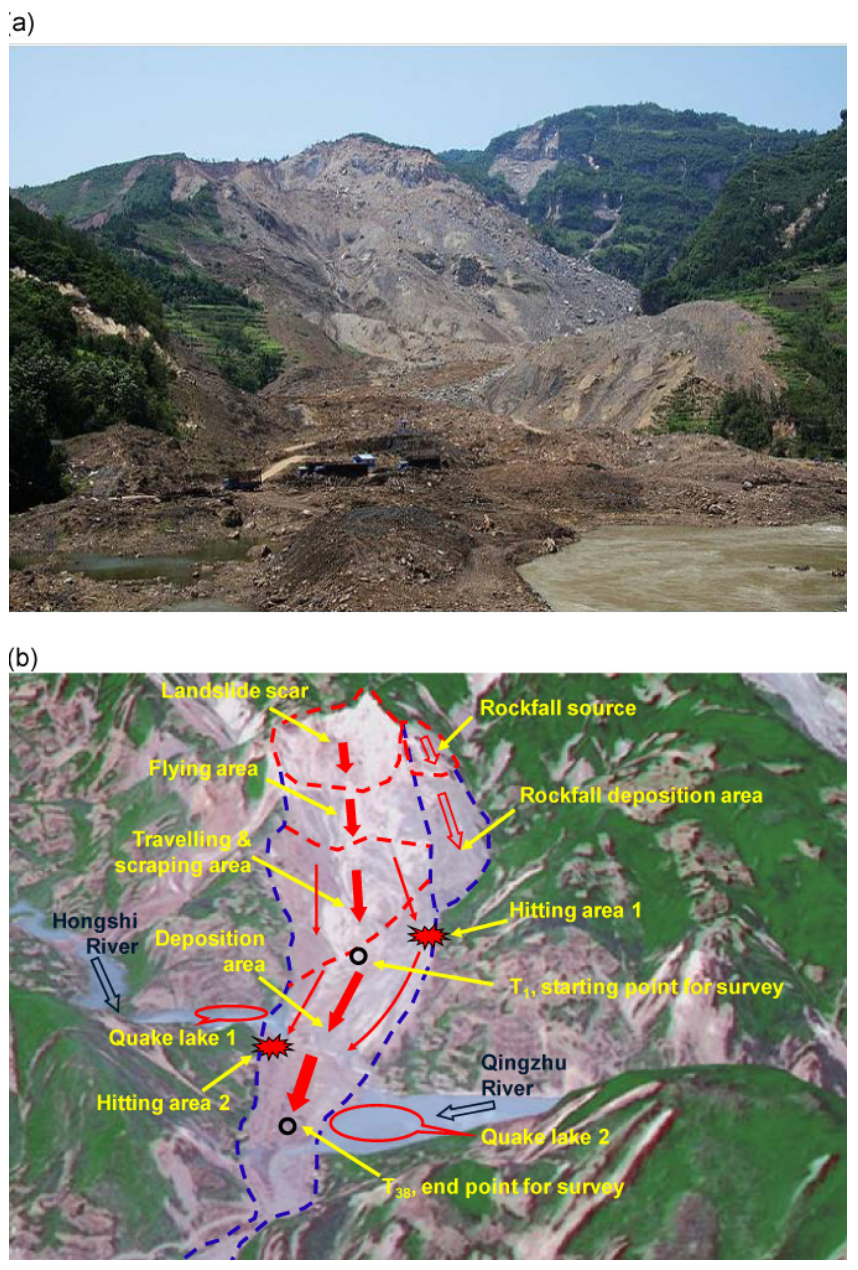

Fig. 2. (a) Full view; (b) remote sensing image of the Donghekou landslide.

\section{Donghekou landslide}

\subsection{Geological and topographic settings}

The Donghekou landslide $\left(105^{\circ} 6^{\prime} 31^{\prime \prime} \mathrm{E}, 32^{\circ} 24^{\prime} 23^{\prime \prime} \mathrm{N}\right)$ is located at Donghekou Village, Qingchuan Country, Sichuan, which is approximately $3 \mathrm{~km}$ to the north of the YinxiuBeichuan-Qingchuan fault that triggered the Wenchuan earthquake. Figure 1 shows the overview of the original area of Donghekou before the landslide occurred. It is a middle and low mountainous area in geomorphology, consisting mainly of dolomitic limestone, dark gray and dark siliceous shale, and carbonaceous sericite quartz phyllite. The upper part comprising dolomitic limestone has a sharp slope with gradients of $70^{\circ}-80^{\circ}$ due to a gully cutting. In contrast, the middle and lower part comprising siliceous shale and carbonaceous phyllite has a relatively gentle slope with gradients of $20^{\circ}-30^{\circ}$. The V-shaped valley at the slope toe (Fig. 1) provides a favourable topography for the occurrence of potential flow-type landslides, which are often associated with long run-out distances (Wen et al., 2004). 

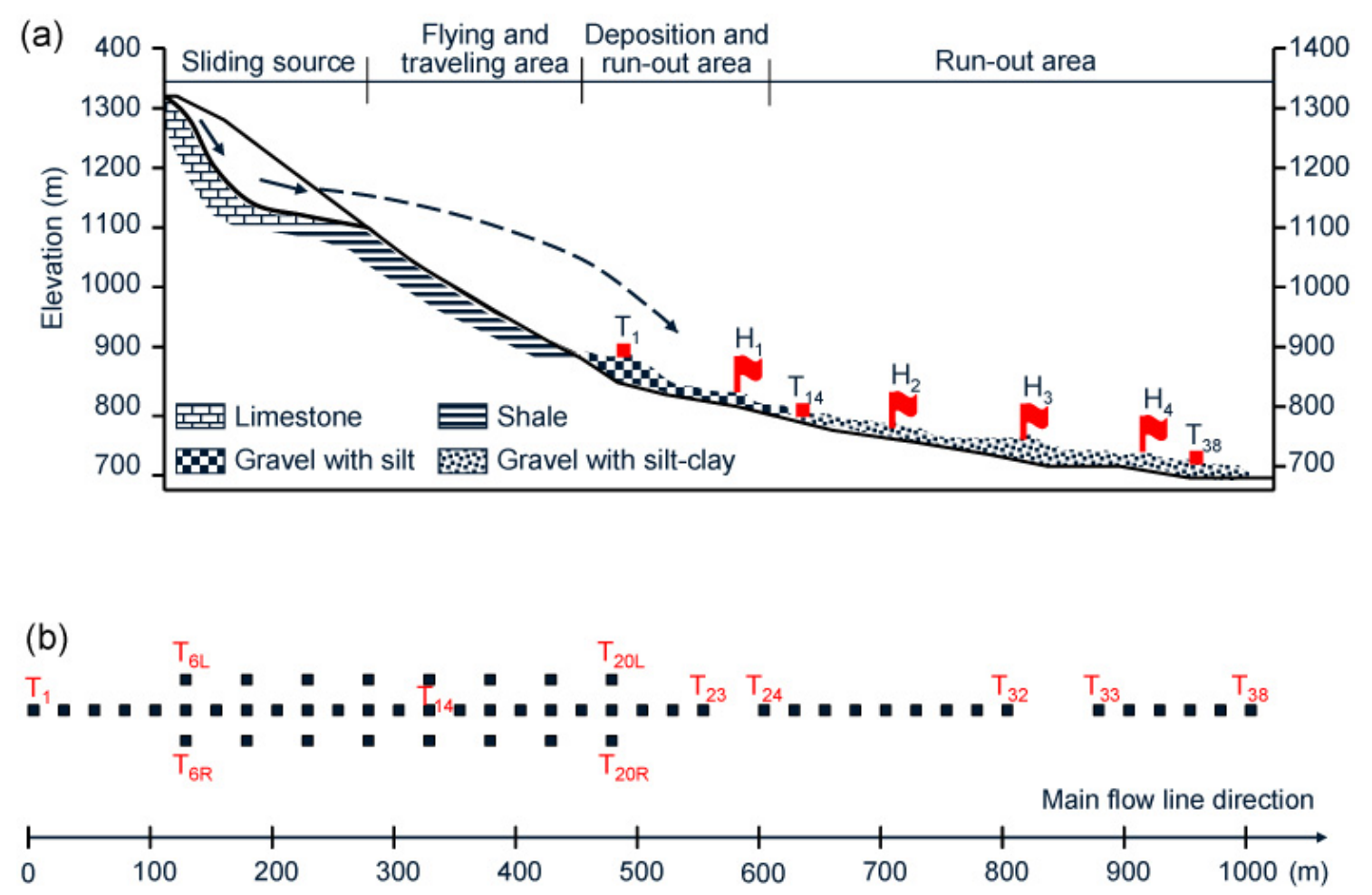

Fig. 3. (a) Schematic cross-section of the Donghekou landslide (four local highlands of $\mathrm{H}_{1}-\mathrm{H}_{4}$ are labelled with flags); (b) layout of sampling locations along the main flow line.

\subsection{The landslide}

At Donghekou, the earthquake lasted approximately $80 \mathrm{~s}$. The prolonged ground shaking caused a shattering-ejection type of landslide (Fig. 2) with a total volume of approximately 30 million $\mathrm{m}^{3}$ (Huang, 2008), which caused the loss of approximate 700 people (Xie et al., 2008). It is a typical rapid and long run-out landslide with a height between the scar and toe of approximately $700 \mathrm{~m}$, a length of $2700 \mathrm{~m}$, a width of $150-600 \mathrm{~m}$, and a covering area of $1.09 \mathrm{~km}^{2}$. The thickness of the landslide deposits varies greatly, from several meters to dozens of meters. The residual deposits at the landslide scar and the deposits near the frontal area have a relatively large thickness of $50-70 \mathrm{~m}$ and $30-40 \mathrm{~m}$, respectively. The landslide also blocked two rivers, the Qingzhu River and the Hongshi River (a tributary to the Qingzhu River), resulting in two quake lakes shown in Fig. 2b (Chang et al., 2011). These two lakes were drained by means of division channels excavated after the earthquake.

According to the characteristics of movement and deposition, the Donghekou landslide can be divided into three main areas: sliding source, flying and travelling area, and deposition and run-out area (Figs. $2 b$ and $3 a$ ). In general, the landslide has a carrot shape with a wide sliding source and a narrow but long deposition and run-out area due to the constraint of topography. The sliding source is located at elevations be- tween $1080 \mathrm{~m}$ and $1330 \mathrm{~m}$, consisting of highly weathered dolomitic limestone on a shale bedding that is a favourable contact interface for the slip zones. During the earthquake, approximately $6 \times 10^{6} \mathrm{~m}^{3}$ of dolomitic limestone detached from what became the scar with a shape of convex in the middle but concave on the lateral sides (Fig. 2). The sliding mass was thrown under the vertical force of the earthquake and crushed in front of a platform formed at the top (Yin et al., 2009). Much of the rock mass was projected for a distance and crashed onto the valley floor in the initial deposition and run-out area at elevations of 800-900 m (Fig. 3a). Due to the scraping effect of the high-speed mass movement, the original loose deposits and vegetation on the valley floor were ripped off the slope as shown in Fig. 2 as the flying and travelling area. The debris then ran down the hill and deposited over a distance of approximately $1500 \mathrm{~m}$.

The direction of the main mass movement changed twice along the travel path at two obstructive mountainsides (Figs. 2 and 4). The debris flow with high speed hit and shaved the left side of the first obstructive mountain, then changed the route of movement (Fig. 4a). Unlike the scenario at the first obstructive mountain, part of the flowing debris stopped after hitting the right side of the second obstructive mountain and climbed up about $20 \mathrm{~m}$ (Fig. 4b). That might be caused by two factors: (1) the deposit traveled at a moderate speed not as high as that at the first obstructive 
(a)

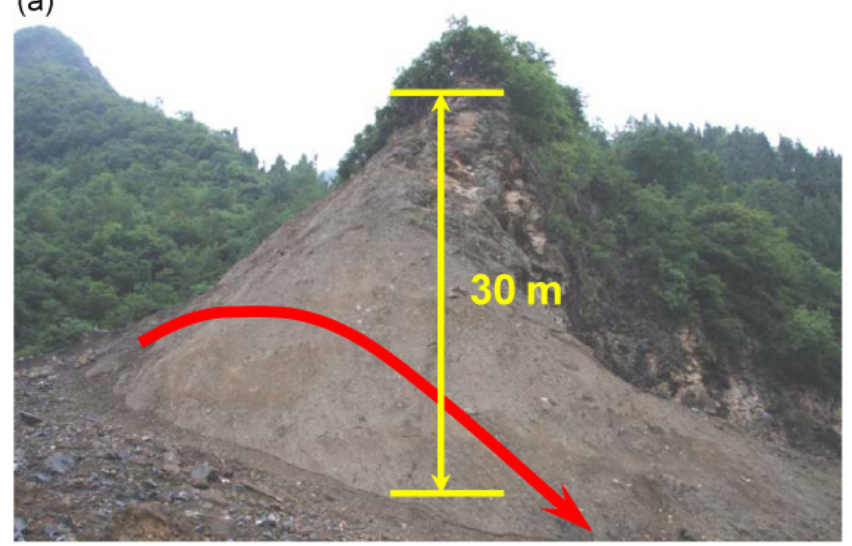

(b)

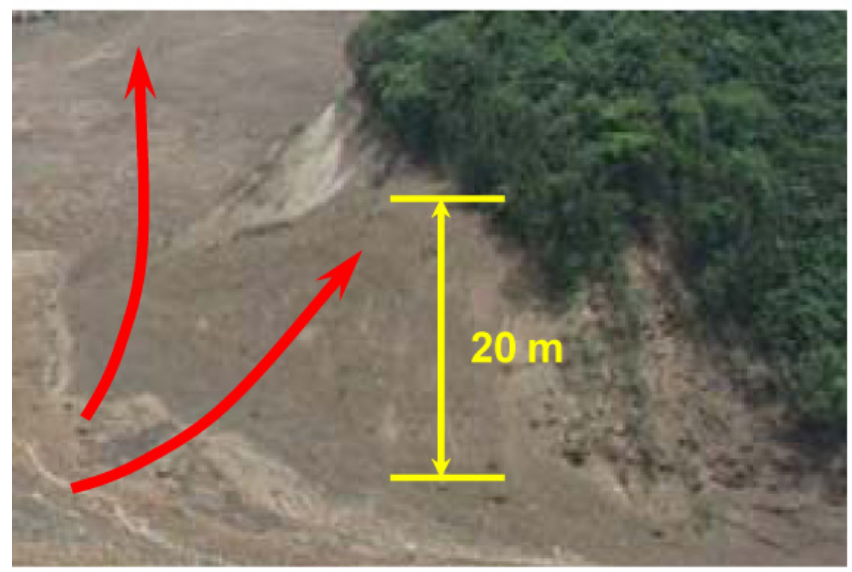

Fig. 4. (a) Hitting area 1; (b) hitting area 2 for the main mass movement along the travel path.

mountain; and (2) the deposit comprised more broken soils and rocks than that at the first obstructive mountain. Then the mass flow changed the direction again and entered the Qingzhu River, resulting in a huge wave. A witness was dragged by the wave into the river but luckily rescued on the downstream. The witness heard a tremendous air explosion all of a sudden at the time of the failure. This illustrates that the landslide flow was extremely rapid, which has also been reported by Wang et al. (2009).

\section{Test plan and procedures of field investigation}

Shortly after the earthquake, we conducted field surveys at the Donghekou landslide deposit amidst numerous aftershocks. The surveys included identification of particle flow paths and measurements of the particle size, density, and fabric of the landslide debris along the flow paths. Among various factors that can produce particle segregation under certain circumstances, particle size is found to be the most important (Williams, 1976). Therefore, great efforts were (a)
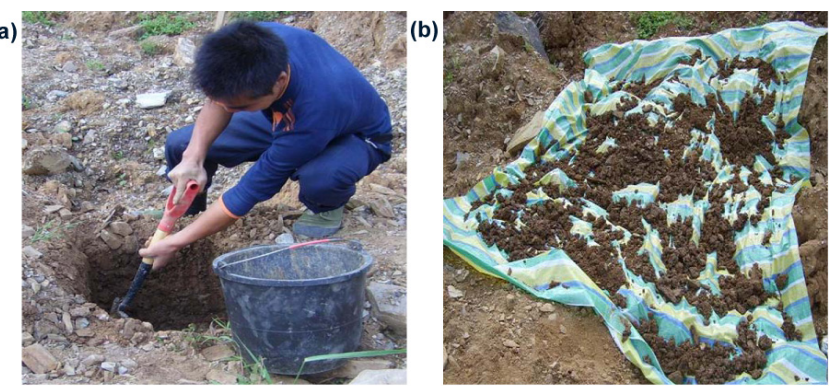

(c)
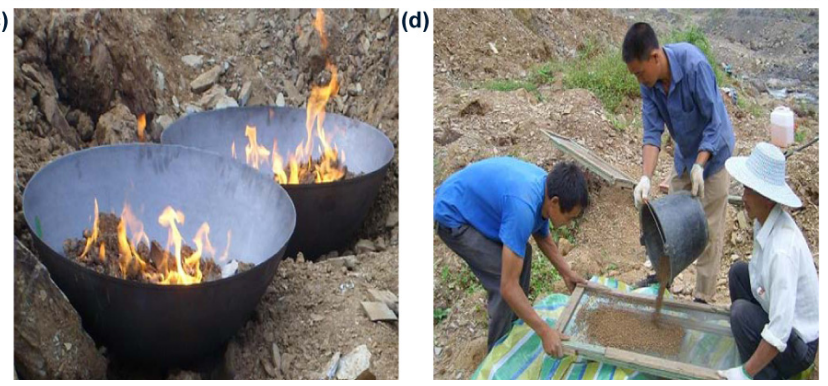

Fig. 5. Sieve analysis for the fine-to-medium fraction of the deposit materials. (a) digging of block samples; (b) sun-drying of sample soils; (c) re-drying sample soils by gasoline burning; (d) soil sieving.

made to investigate the particle size of the landslide deposit in this study. However, the investigation of the particle size distribution of landslide debris has never been standardised and is usually assessed by a partial estimation through the analysis of the finer fraction because landslide debris materials often range in size from blocks of tens of cubic metres to clay particles (Casagli et al., 2003). In our field surveys, three methods were adopted, including sieve and hydrometer analysis of fine particles in the laboratory, field sieve analysis of the fine-to-medium fraction (Fig. 5) and grid-by-number analysis of the very coarse fraction (Fig. 6). The samples were tested at a temporary test site on the landslide deposit. A small amount of soil from each block sample was taken for parallel testing in the laboratory. The field surveys were completed before the originally fresh soil deposit was disturbed by an intensive storm $(180 \mathrm{~mm}$ of precipitation) on 23-24 September 2008.

In the field surveys, the grain-size distribution of the soil particles smaller than $100 \mathrm{~mm}$ was measured using the sieve analysis method. The grain-size distribution and dry unit weight of each of the samples were measured following the standard methods of ASTM (2000). Figure 5 shows the field testing procedure for sieve analysis. To obtain a relatively accurate result of soil sieving, double drying of sample soils, including sun-drying and gasoline-burning drying, were carried out to make sample soils as dry as possible. Special large-size sieves and gasoline-burning devices were prepared and used to assist testing approximately six tones of soil samples on the site. Such a non-standard drying method was 


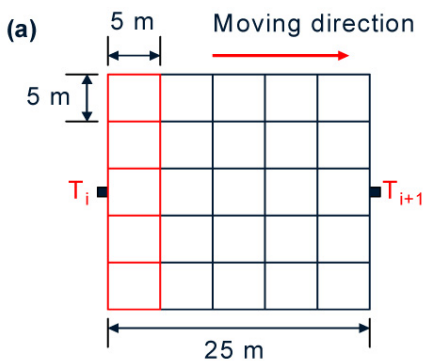

(b)

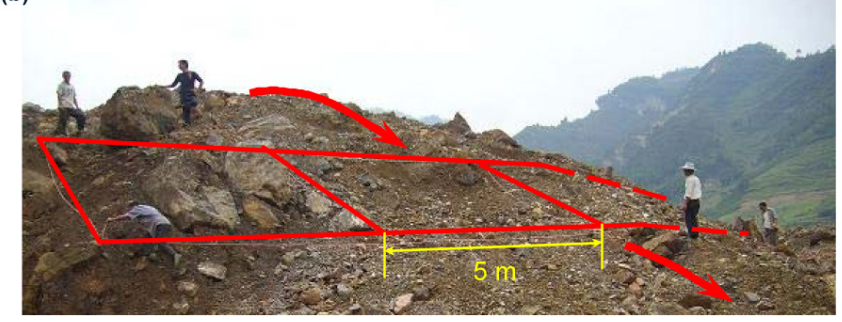

Fig. 6. Grid-by-number analysis for the coarser fraction of the deposit materials along a $1000 \mathrm{~m}$ long segment of the flow line. (a) Schematic grid for surveying large particles; (b) surveying large particle.

adopted to dry approximately $6500 \mathrm{~kg}$ of soil on site. The testing of such a large amount of soil would have been impossible if the soil had to be transported to a laboratory for oven drying.

The starting and ending sampling locations $\left(\mathrm{T}_{1}\right.$ and $\left.\mathrm{T}_{38}\right)$ for field tests and surveys are shown in Figs. 2 and 3. Sampling location $\mathrm{T}_{14}$ is located at the boundary between the zone of gravel with silt and the zone of gravel with silt-clay (Figs. 3 and 8 b). In total, 54 block samples, $400 \times 400 \times$ $400 \mathrm{~mm}$ in size, were taken manually at the surface along the main flow line and two side flow lines. Figure 3 shows the sampling layout along the run-out distance of $1000 \mathrm{~m}$. The distance between two neighbouring sampling locations was $25 \mathrm{~m}$, except the distance $(50 \mathrm{~m})$ between $\mathrm{T}_{23}$ and $\mathrm{T}_{24}$ due to the presence of a breach (Fig. 8d) and the distance ( $75 \mathrm{~m}$ ) between $T_{32}$ and $T_{33}$ where a temporary emergency road was constructed after the earthquake. The particle size distributions of these 54 samples were obtained using sieve analysis and the corresponding in-situ bulk densities were measured.

Due to the sample size limitation, the grain size of particles larger than $100 \mathrm{~mm}$ was determined in-situ through a grid-by-number analysis, with the smallest grid being $5 \times 5 \mathrm{~m}$ in size. Rectangular girds of $25 \mathrm{~m} \times 5 \mathrm{~m}$, each containing five cells of $5 \mathrm{~m} \times 5 \mathrm{~m}$ as shown in Fig. 6, were surveyed sequentially along a $1000 \mathrm{~m}$ long flow line. Within each cell, five groups of particles were identified according to their diameter ranges $(11-30 \mathrm{~cm}, 31-50 \mathrm{~cm}, 51-100 \mathrm{~cm}$, $101-300 \mathrm{~cm},>300 \mathrm{~cm}$ ) and the numbers of different-sized particles were counted. The total numbers of different-sized
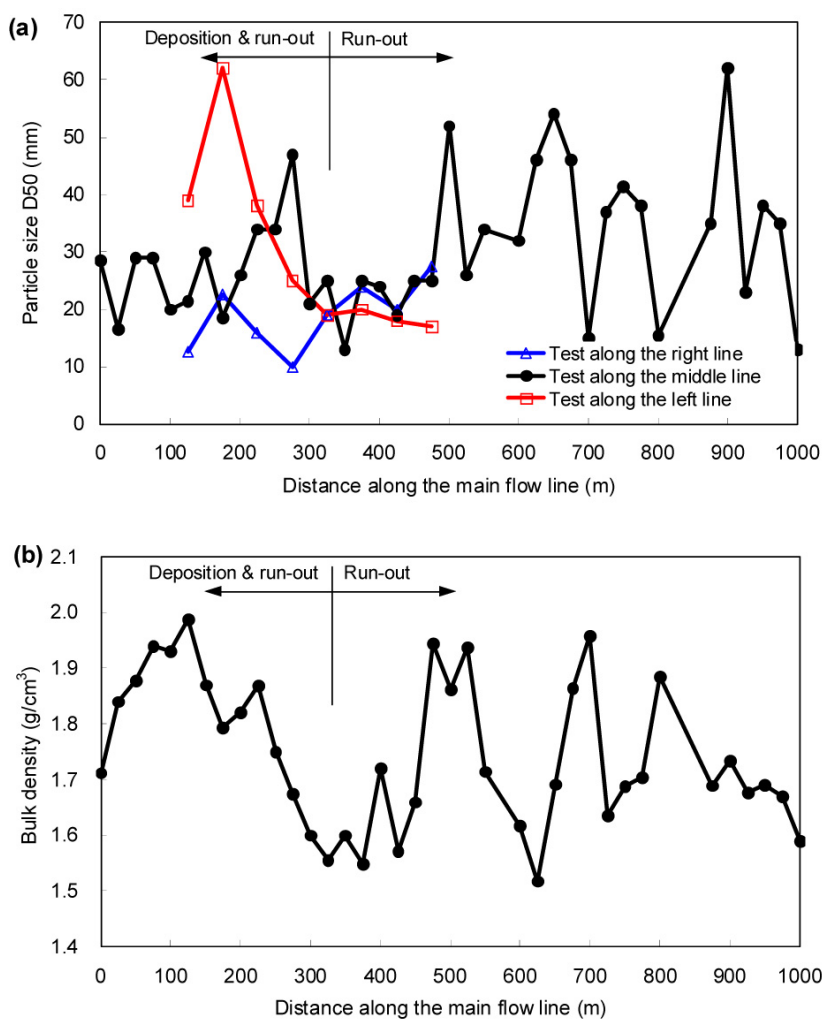

Fig. 7. (a) Variation of particle size $D_{50}$ along three flow lines; (b) variation of bulk density along the main flow line.

particles within a square grid of $25 \mathrm{~m} \times 25 \mathrm{~m}$ are used for statistical analysis. The surveys were conducted sequentially over a 1000-m range along the main flow line from the starting point $\left(\mathrm{T}_{1}\right)$ to the ending point $\left(\mathrm{T}_{38}\right)$ as shown in Fig. 3 at an advancing interval of $5 \mathrm{~m}$.

\section{Results and discussion}

\subsection{Segregation of fine particles}

The grain size distribution of a soil can be represented by several characteristic particle diameters of the soil, namely $D_{60}, D_{50}, D_{30}$, and $D_{10}$ (particle diameters at $60,50,30$ and $10 \%$ percent finer by weight). The values of these characteristic diameters at 38 sampling locations along a $1000 \mathrm{~m}$ long segment of the main flow line are presented in Table 1. The variations in the mean particle size, $D_{50}$, along the main flow line are shown in Fig. 7a and discussed to illustrate how these characteristic diameters vary along the flow line. The values of $D_{50}$ are mostly in the range of $10-60 \mathrm{~mm}$ and exhibit a weakly increasing trend with increased run-out distance. The fluctuations of $D_{50}$ become progressively larger with increased run-out distance. In an ideal particle flow without crushing, $D_{50}$ would increase with increased run-out 

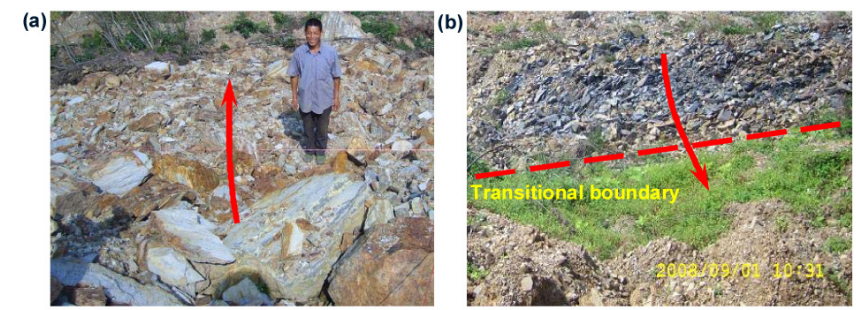

(c)
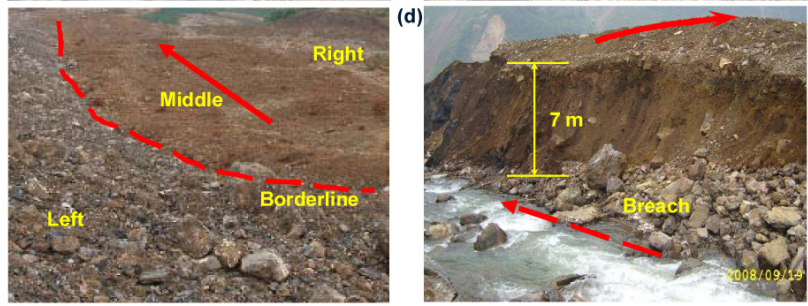

(e)
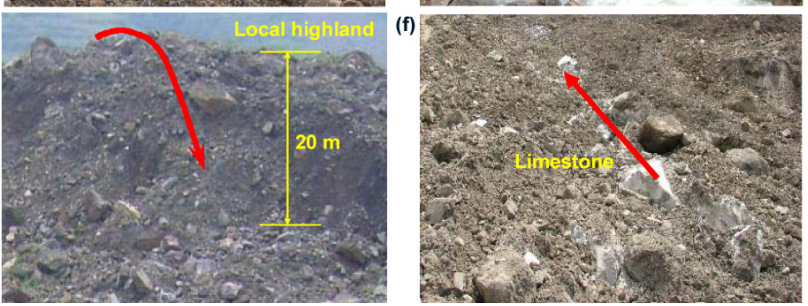

Fig. 8. Local geographic and soil conditions along the main flow line. (a) The initial zone with large quantities of rocks and gravel; (b) transitional zone; (c) the zone with the right part lying over the left part; (d) the breach associated with Quake lake 1 in Fig. 2; (e) the third local highland; (f) the frontal zone with limestone from the landslide scar distributed along the flow line.

distance more markedly (Jullien and Meakin, 1990; Iverson and Vallance, 2001). The reason for the weaker trend in the present study is that the landslide debris underwent disintegration, particle crushing, and mixing with local landslide materials as it moved down the valley. This can be clearly seen by comparing the particles in the initial deposition area (Fig. 8a) and the frontal area (Fig. 8f). The deposit in Fig. 8a is mainly comprised of rocks and gravel and it is more uniform in particle size than that in Fig. 8f, which is comprised of silt with scattered rocks and gravel.

In Fig. 7a, four local maximum values of $D_{50}$ correspond to the four local highlands, $\mathrm{H}_{1}-\mathrm{H}_{4}$, in Fig. 3a. This observation confirms that the segregation mechanism works by inverse grading, with large particles moving to the top and small particles accumulating at the bottom (Miyamoto et al., 2007). The percolation of fine particles and the rise of coarse particles took place (Iverson and Vallance, 2001). For instance, Fig. 8e shows the third local highland, $\mathrm{H}_{3}$, with the feature of inverse grading on a $20 \mathrm{~m}$ high exposure. The thin surface layer with a cluster of boulders lies on a layer of primarily sandy silt with scattered floating boulders. Similar inverse grading phenomenon was also observed in a large landslide that occurred in Siaolin Village in southern Taiwan on 9 September 2009 (Lee et al., 2009). In that catastrophic
Table 1. Particle size distributions of the landslide debris finer than $100 \mathrm{~mm}$ at the 38 sampling locations along the 1000-m flow line investigated in this study.

\begin{tabular}{|c|c|c|c|c|c|}
\hline \multirow{2}{*}{$\begin{array}{c}\text { Sampling } \\
\text { point }\end{array}$} & \multirow{2}{*}{$\begin{array}{c}\text { Distance from } \\
\mathrm{T}_{1} \\
(\mathrm{~m})\end{array}$} & \multicolumn{4}{|c|}{ Particle diameter $(\mathrm{mm})$} \\
\hline & & $D_{60}$ & $D_{50}$ & $D_{30}$ & $D_{10}$ \\
\hline $\mathrm{T}_{1}$ & 0 & 39.0 & 28.5 & 12.0 & 2.9 \\
\hline $\mathrm{T}_{2}$ & 25 & 26.0 & 16.5 & 5.9 & 1.0 \\
\hline $\mathrm{T}_{3}$ & 50 & 40.0 & 29.0 & 12.5 & 2.7 \\
\hline $\mathrm{T}_{4}$ & 75 & 42.0 & 29.0 & 11.5 & 2.9 \\
\hline $\mathrm{T}_{5}$ & 100 & 31.0 & 20.0 & 6.5 & 1.3 \\
\hline $\mathrm{T}_{6}$ & 125 & 29.5 & 21.5 & 9.0 & 2.3 \\
\hline $\mathrm{T}_{7}$ & 150 & 43.0 & 30.0 & 12.5 & 2.9 \\
\hline $\mathrm{T}_{8}$ & 175 & 28.5 & 18.5 & 6.8 & 2.0 \\
\hline $\mathrm{T}_{9}$ & 200 & 40.0 & 26.0 & 9.5 & 2.3 \\
\hline $\mathrm{T}_{10}$ & 225 & 49.0 & 34.0 & 13.5 & 3.2 \\
\hline $\mathrm{T}_{11}$ & 250 & 47.0 & 34.0 & 14.0 & 2.7 \\
\hline $\mathrm{T}_{12}$ & 275 & 61.0 & 47.0 & 15.0 & 3.0 \\
\hline $\mathrm{T}_{13}$ & 300 & 30.0 & 21.0 & 9.4 & 2.2 \\
\hline $\mathrm{T}_{14}$ & 325 & 41.0 & 25.0 & 8.0 & 1.4 \\
\hline $\mathrm{T}_{15}$ & 350 & 20.5 & 13.0 & 5.4 & 1.2 \\
\hline $\mathrm{T}_{16}$ & 375 & 38.0 & 25.0 & 10.0 & 2.1 \\
\hline $\mathrm{T}_{17}$ & 400 & 37.0 & 24.0 & 8.0 & 1.5 \\
\hline $\mathrm{T}_{18}$ & 425 & 27.0 & 19.0 & 8.0 & 1.3 \\
\hline $\mathrm{T}_{19}$ & 450 & 40.0 & 25.0 & 8.2 & 1.6 \\
\hline $\mathrm{T}_{20}$ & 475 & 42.0 & 25.0 & 7.5 & 0.9 \\
\hline $\mathrm{T}_{21}$ & 500 & 63.0 & 52.0 & 14.0 & 1.5 \\
\hline $\mathrm{T}_{22}$ & 525 & 43.0 & 26.0 & 8.0 & 1.8 \\
\hline $\mathrm{T}_{23}$ & 550 & 50.0 & 34.0 & 13.5 & 3.5 \\
\hline $\mathrm{T}_{24}$ & 600 & 45.0 & 32.0 & 13.0 & 3.0 \\
\hline $\mathrm{T}_{25}$ & 625 & 60.0 & 46.0 & 16.5 & 3.7 \\
\hline $\mathrm{T}_{26}$ & 650 & 66.0 & 54.0 & 21.0 & 4.3 \\
\hline $\mathrm{T}_{27}$ & 675 & 61.0 & 46.0 & 13.0 & 1.0 \\
\hline $\mathrm{T}_{28}$ & 700 & 23.0 & 15.0 & 5.5 & 0.8 \\
\hline $\mathrm{T}_{29}$ & 725 & 47.0 & 37.0 & 19.0 & 4.7 \\
\hline $\mathrm{T}_{30}$ & 750 & 57.0 & 41.5 & 14.0 & 2.3 \\
\hline $\mathrm{T}_{31}$ & 775 & 56.0 & 38.0 & 11.5 & 1.4 \\
\hline $\mathrm{T}_{32}$ & 800 & 23.0 & 15.5 & 5.6 & 0.65 \\
\hline $\mathrm{T}_{33}$ & 875 & 54.0 & 35.0 & 8.0 & 0.7 \\
\hline $\mathrm{T}_{34}$ & 900 & 71.0 & 62.0 & 20.0 & 2.1 \\
\hline $\mathrm{T}_{35}$ & 925 & 36.0 & 23.0 & 7.0 & 0.63 \\
\hline $\mathrm{T}_{36}$ & 950 & 54.0 & 38.0 & 14.0 & 2.3 \\
\hline $\mathrm{T}_{37}$ & 975 & 54.0 & 35.0 & 9.3 & 0.8 \\
\hline $\mathrm{T}_{38}$ & 1000 & 22.0 & 13.0 & 4.3 & 0.62 \\
\hline
\end{tabular}

landslide event, the landslide volume was 23.9 million $\mathrm{m}^{3}$ and the deposition and run-out distance was over $1600 \mathrm{~m}$. Reversely graded bedding was found in the deposits in the travelling area. Zhou (2010) summarized that two stages might exist for particle segregation in a deposition process. In the first stage, most of coarse particles flow upwards and concentrate in the top layers while fine particles are squeezed into the bottom layer, which is referred to as a squeeze expulsion mechanism. In the second stage, strong shearing occurs in the layers near the free surface and fine particles 

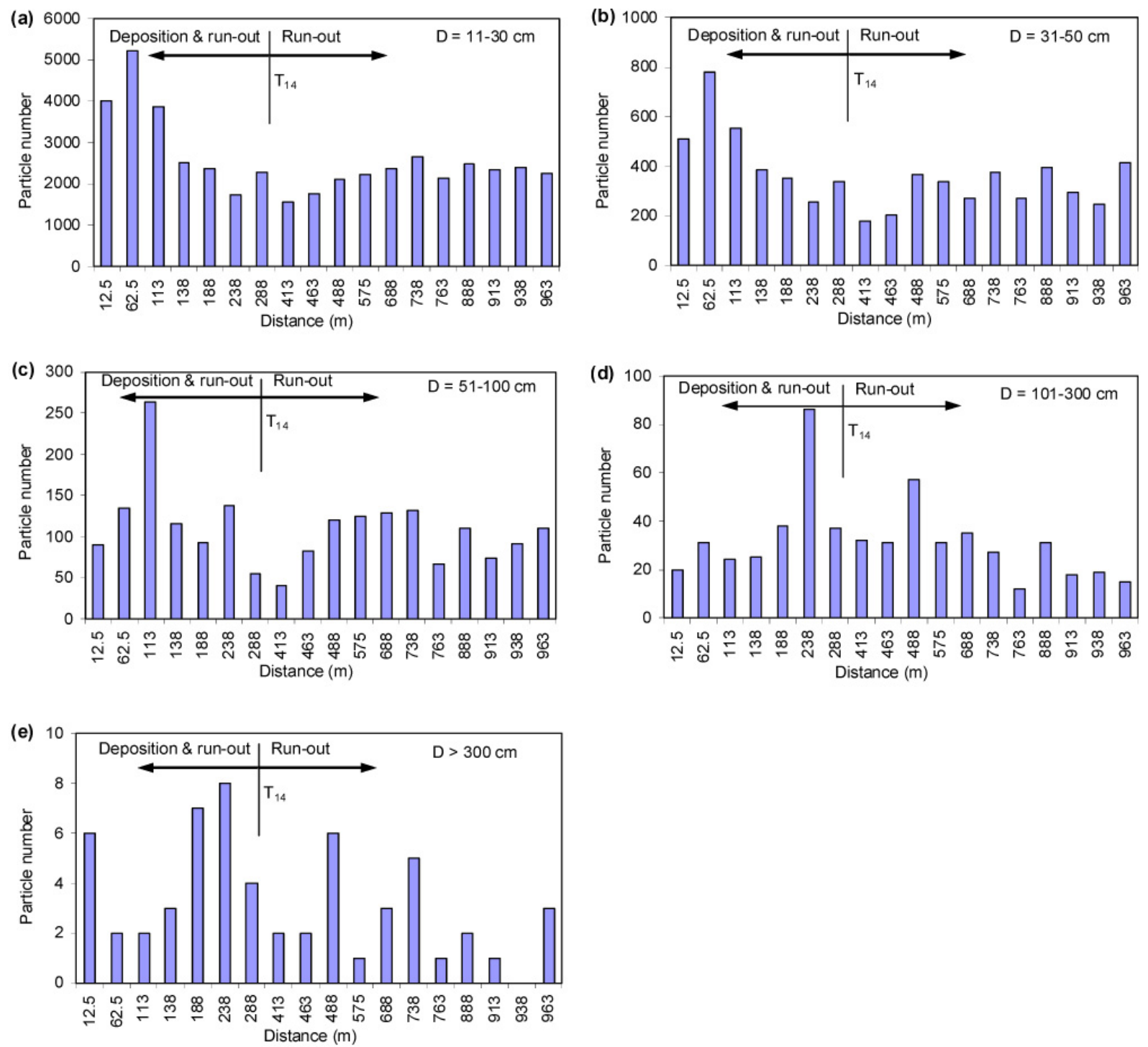

Fig. 9. Variations in the numbers of different-sized particles within each $25 \mathrm{~m} \times 25 \mathrm{~m}$ cell with distance along the main flow line. (a) Particles with diameters of 11-30 cm; (b) particles with diameters of 31-50 cm; (c) particles with diameters of 51-100 cm; (d) particles with diameters of 101-300 cm; (e) particles with diameters larger than $300 \mathrm{~cm}$.

are observed penetrating into the granular body through the voids formed by coarse particles, which is referred to as a kinematic sieving mechanism. Therefore, both mechanical (squeeze expulsion) and geometrical (kinematic sieving) effects contribute to particle segregation in the flow deposition process.

To understand the particle sorting in the initial accumulation area, the variations of $D_{50}$ along the left and right sides of the main flow line (Fig. 3b) are compared in Fig. 7a. Two features are observed: the value of $D_{50}$ on the left is larger than that on the right at a small distance; after a critical distance of about $350 \mathrm{~m}$ (the transitional zone in Figs. 3 and $8 \mathrm{~b}$ ), the values of $D_{50}$ on the left, in the middle, and on the right become less differentiable. This observation agrees well with the material composition of the landslide. The wide initial accumulation area can be divided into two parts involving two distinct types of deposits with an obvious borderline shown in Fig. 8c. The left part is comprised of gravel with a small fines content while the right part is comprised of soil with some gravel. As the deposit travelled down the slope, the right part tended to lay over and mix with the middle and left parts due to the topographical constraints (Fig. 8c), and hence the material variability along the transverse line became less significant.

The variations in the soil bulk density with the run-out distance along the main flow line are shown in Fig. 7b. The bulk density ranges from 1.5 to $2.0 \mathrm{~g} \mathrm{~cm}^{-3}$. Two locations of low bulk densities are notable in the transitional zone at a distance 
of 325-375 m (Fig. 8b) and in the breach zone at a distance of $625 \mathrm{~m}$ (Fig. 8d). In the transition zone, the materials were mainly from "free fall" and not subjected to much transportation and mixing. The breach zone, on the other hand, was a potential lowland filled with relatively fine particles. The bulk density values in Fig. 7b do not correspond well to the $D_{50}$ values in Fig. 7 a as $D_{50}$ only represents a part of the landslide composition.

\subsection{Segregation of coarse particles}

The variations in the numbers of five groups of coarse particles within a $25 \mathrm{~m} \times 25 \mathrm{~m}$ cell (diameter $=11-30 \mathrm{~cm}, 31-$ $50 \mathrm{~cm}, 51-100 \mathrm{~cm}, 101-300 \mathrm{~cm},>300 \mathrm{~cm}$ ) with the run-out distance are shown in Fig. 9. The characteristics of the mass movement are different in the initial deposition and run-out area and the frontal run-out area (Figs. 2 and 3). In the initial deposition and run-out area, the rock mass projected by the action of the earthquake landed on the valley floor at high speed. The grids in which the maximum numbers of different-sized large particles occur (Fig. 9) are all in the initial deposition and run-out area. The locations of these grids for the five particle groups are at $62.5 \mathrm{~m}, 62.5 \mathrm{~m}, 113 \mathrm{~m}$, $238 \mathrm{~m}$, and $238 \mathrm{~m}$, respectively, from the starting sampling point, $\mathrm{T}_{1}$. The flying distance of particles in a particular particle-diameter range tends to increase with the mean particle diameter. This can be explained by the mechanism of trajectory segregation (Anderson and Bunas, 1993), in which the distance that a particle travels after being projected, termed as the stopping distance, is proportional to the square of the particle diameter.

In the run-out zone starting from $\mathrm{T}_{14}\left(325 \mathrm{~m}\right.$ from $\left.\mathrm{T}_{1}\right)$, no projected debris was deposited and the materials simply flowed down the valley. Near the transition line at $\mathrm{T}_{14}$, the large particles in all the five diameter groups appear to be minimal and the soil density is low. The numbers of large particles in the first two diameter groups (diameter $=11-30 \mathrm{~cm}$ and $31-50 \mathrm{~cm}$ ) increase with the run-out distance along the main flow line and reach relatively constant values (Fig. 9a and b). The run-out distance from $\mathrm{T}_{14}$ at which the maximum particle number is found is defined as the characteristic flow distance. The characteristic flow distances for the above two particle groups are $338 \mathrm{~m}$ and $138 \mathrm{~m}$, respectively. The trend in the run-out zone in Fig. 9a and b agrees with that observed in typical particle flows (Anderson and Bunas, 1993): after a characteristic flow distance, the deposition of large particles tends to be steady. However, the observed characteristic flow distances do not increase with the particle diameter as expected in an idealized particle flow. The numbers of very large particles in the last three diameter groups $($ diameter $=51-100 \mathrm{~cm}, 101-300 \mathrm{~cm}$, and $>300 \mathrm{~cm}$ ) do not increase with the run-out distance. Instead they appear to decrease along the main flow line (Fig. 9c-e). There are two mechanisms at work in this landslide event. On one hand, particle flow caused larger particles to travel further

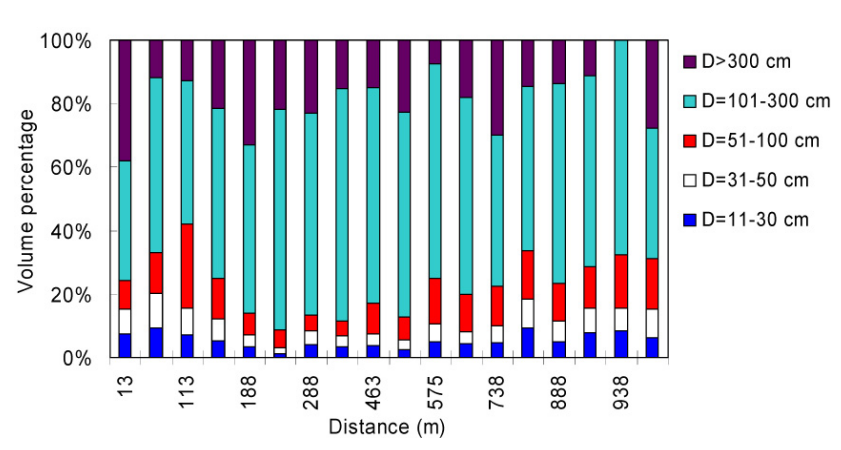

Fig. 10. Variations in volume percentages of the five groups of particles.

away from the scar. On the other hand, the released rock mass/aggregates disintegrated and large particles broke along the flow path due to internal interactions and impacts with the boundaries, leading to more small particles (Figs. 7a, 9a and b) and fewer large particles (Fig. 9c-e) along the flow path.

The variations in the volume percentages of the five groups of particles with the run-out distance are shown in Fig. 10. A specific-sized particle is assumed as a sphere for volume calculation. The representative diameter values are assumed to be $20 \mathrm{~cm}, 40 \mathrm{~cm}, 75 \mathrm{~cm}, 2 \mathrm{~m}$, and $3 \mathrm{~m}$ for the five groups of particles, respectively. As indicated in Fig. 10, the volume of particles with diameters of $1-3 \mathrm{~m}$ is the largest along the main flow line. Note that the volume percentages reported here are for the particles on the surface of the landslide deposit, not for those particles within a unit volume of material in the deposit.

Based on the above surveying results for both fine and coarse particles, it is found that the process of particle sorting and fabric changes during a large landslide differs from processes occurring in an ideal granular mass flow in a number of ways. First, the large landslide process involves the detachment of a vast amount of rock mass from the landslide scar. The rock mass disintegrates and large particles break gradually along the movement path. Second, the grain sizes of landslide materials are widely distributed, ranging from nanometers to a few meters. Third, the mass movement in an earthquake-induced landslide involves projection, longdistance flying, sliding, rolling, trajectory segregation, inverse grading, etc. It is extremely challenging to simulate the entire process of particle sorting and fabric changes, which requires further large-scale field tests/investigations and robust theoretical studies.

\section{Conclusions}

A field study was carried out on a large landslide of approximately 30 million $\mathrm{m}^{3}$ triggered by the 12 May 2008 Wenchuan earthquake. The particle run-out distance during the landslide process reached over $2000 \mathrm{~m}$. Particle flows in 
the landslide process were studied through field surveys of changes in the soil particle size, fabric, and density along the particle movement paths. The field study was completed before the originally fresh soil deposit was disturbed. Trajectory segregation, inverse grading and particle crushing were found in the landslide event, which contributed to the heterogeneity of the soil deposits. The following characteristics of particle flow and segregation in the large-scale landslide process were discovered:

1. In the initial deposition area, particles with larger diameters appeared to have flown longer, exhibiting signs of trajectory segregation. Materials from different sources mixed, forming more uniform debris.

2. In the run-out area, the landslide debris underwent disintegration, particle crushing, and mixing with local landslide materials as it moved down the valley. The particle flow tended to cause particles up to $0.5 \mathrm{~m}$ in diameter to travel further. However, particle disintegration and crushing led to more small particles along the movement paths and the observed characteristic flow distances of very large particles greater than $0.5 \mathrm{~m}$ in diameter did not increase with the particle diameter, which is different from observations of an idealized granular mass flow.

3. Inverse grading took place during the particle flow with the percolation of fine particles and the rise of coarse particles. Such inverse grading was particularly apparent at local highlands along the flow path. Both mechanical and geometrical effects contributed to particle segregation in the flow deposition process.

4. Two locations of low bulk densities are notable in the transitional zone (where the materials were mainly from "free fall" and not subjected to much transportation and mixing) and in potential lowlands filled with relatively fine particles.

Acknowledgements. We thank the support from the State Key Laboratory of Geohazard Prevention and Geoenvironment Protection of Chengdu University of Technology, Ministry of Science and Technology of China (Grant No. 2009BAK56B05) and the Research Grants Council of the Hong Kong SAR (Grant No. 622207).

Edited by: M. E. Contadakis

Reviewed by: J. H. Zhang and C.-T. Lee

\section{References}

American Society for Testing and Materials: D422-63, Standard test method for particle-size analysis of soils: Annual Book of ASTM Standards, 2000.

Anderson, R. S. and Bunas, K. L.: Grain size segregation and stratigraphy in aeolian ripples modelled with a celluar automaton, Nature, 365, 740-743, 1993.
Casagli, N., Ermini, L., and Rosati, G.: Determining grain size distribution of the material composing landslide dams in the Northern Apennines: sampling and processing methods, Eng. Geol., 69, 83-97, 2003.

Chang, D. S. and Zhang, L. M.: Simulation of the erosion process of landslide dams due to overtopping considering variations in soil erodibility along depth, Nat. Hazards Earth Syst. Sci., 10, 933-946, doi:10.5194/nhess-10-933-2010, 2010.

Chang, D. S., Zhang, L. M., Xu, Y., and Huang, R. Q.: Field testing of erodibility of two landslide dams triggered by the 12 May Wenchuan earthquake, Landslides, 1-12, doi:10.1007/s10346011-0256-x, in press, 2011.

Costa, J. E. and Schuster, R. L.: The formation and failure of natural dams, Geol. Soc. Am. Bull., 100, 1054-1068, 1988.

Cui, P., Zhu, Y. Y., Han, Y. S., Chen, X. Q., and Zhuang, J. Q.: The 12 May Wenchuan earthquake-induced landslide lakes: distribution and preliminary risk evaluation, Landslides, 6(3), 209-223, 2009.

Davies, T. R. H.: Large debris flows: A macro-viscous phenomenon, Acta Mech., 63, 161-178, 1986.

Davies, T. R. H.: Debris flow surges - A laboratory investigation, Mitteilung No. 96 der Versuchsanstalt fur Wasserbau, Hydrologie and Glaziologie an der ETH Zurich, 1988.

Dolgunin, V. N. and Ukolov, A. A.: Segregation modelling of particle rapid gravity flow, Powder Technol., 26, 95-103, 1995.

Gray, J. M. N. T., and Thornton, A. R.: A theory for particle size segregation in shallow granular free-surface flows, P. Roy. Soc. A: Math. Phy., 461, 1447-1473, 2005.

Huang, R. Q.: Preliminary analysis of the development, distributions, and mechanisms of the geohazards triggered by the Great Wenchuan Earthquake, State Key Laboratory of Geohazards Prevention and Geological Environment Protection, Chengdu University of Technology, Chengdu, China, 2008.

Iverson, R. M. and Vallance, J. W.: New views of granular mass flow, Geology, 29, 115-118, 2001.

Jullien, R. and Meakin, P.: A mechanism for particle size segregation in three dimensions, Nature, 344, 425-427, 1990.

Khakhar, D. V., McCarthy, J. J., and Ottino, J. M.: Mixing and segregation of granular materials in chute flows, Chaos, 9, 594610, 1999.

Lacasse, S., Nadim, F., Hoeg, K., and Gregersen, O.: Risk assessment in geotechnical engineering: The importance of engineering judgement, Advances in Geotechnical Engineering, in: The Skempton Conference, Institution of Civil Engineers, London, 856-867, 2004.

Lee, C. T., Dong, J. J., and Lin, M. L.: Geological investigation on the catastrophic landslide in Siaolin Village, Southern Taiwan, Sino-Geotechnics, 122, 87-94, 2009.

Miyamoto, H., Yano, H., Scheeres, D. J., Abe, S., Barnouin-Jha, O., Cheng, A. F., Demura, H., Gaskel, R. W., Hirata, N., Ishiguro, M., Michikami, T., Nakamura, A. M., Nakamura, R., Saito, J., and Sasaki, S.: Regolith migration and sorting on asteroid Ikokawa, Science, 316, 1011-1014, 2007.

Sato, H. P. and Harp, E. L.: Interpretation of earthquake-induced landslides triggered by the 12 May 2008, M7.9 Wenchuan earthquake in the Beichuan area, Sichuan Province, China using satellite imagery and Google Earth, Landslides, 6(2), 153-159, 2009.

Savage, S. B. and Lun, C. K. K.: Particle size segregation in inclined chute flow of dry cohesionless granular solids, J. Fluid Mech., 
189, 311-335, 1988.

Schuster, R. L., Logan, R. L., and Pringle, P. T.: Prehistoric rock avalanches in the Olympic Mountains, Washington, Science, 258, 1620-1621, 1992.

Tang, W. H., Zhang, L. M., and Zheng, Y. R.: Dealing with uncertainty in engineering design for large-scale gravel soil slopes in the Three Gorges Reservoir Zone, in: Geohazards -Technical, Economical and Social Risk Evaluation, Berkeley Electronic Press, CD Rom, 2006.

Thornton, A. R. and Gray, J. M. N. T.: Breaking size segregation waves and particle recirculation in granular avalanches, J. Fluid Mech., 596, 261-284, 2008.

Thornton, A. R., Gray, J. M. N. T., and Hogg, A. J.: A three-phase mixture theory for particle size segregation in shallow granular free-surface flows, J. Fluid Mech., 550, 1-25, 2006.

Vallance, J. W. and Savage, S. B.: Particle segregation in granular flows down chutes, in: IUTAM Symposium on Segregation in Granular Materials, Kluwer, 31-51, 2000.

Wang, F. W., Cheng, Q. G., Highland, L., Miyajima, M., Wang, H. B., and Yan, C. G.: Preliminary investigation of some large landslides triggered by the 2008 Wenchuan earthquake, Sichuan Province, China, Landslides, 6(1), 47-54, 2009.

Wang, G. H. and Sassa, K.: Seismic loading impacts on excess porewater pressure maintain landslide triggered flowslides, Earth Surf. Process. Landforms, 34(2), 232-241, 2009.
Wang, Y. and Hutter, K.: Granular material theories revised, in: Geomorphological fluid mechanics, Berlin Springer-Verlag, 79107, 2001.

Wen, B. P., Wang, S. J., Wang, E. Z., and Zhang, J. M.: Characteristics of rapid giant landslides in China, Landslides, 4(3), 247-261, 2004.

Williams, J. C.: The segregation of particulate materials - A review, Powder Technol., 15, 245-251, 1976.

Xie, H. P., Deng, J. H., Tai, J. J, He, C. R., Wei, J. B., Chen, J. P., and Li, X. Y.: Wenchuan Earthquake and post-earthquake reconstruction-related geotechnical problems, Chin. J. Mech. Eng., 27, 1781-1791, 2008 (in Chinese).

Yin, Y. P., Wang, F. W., and Sun, P.: Landslide hazards triggered by the 2008 Wenchuan earthquake, Sichuan, China, Landslides, 6(2), 139-152, 2009.

Zhang, L. M.: Challenges in multi-hazard risk assessment and management: Geohazard chain in Beichuan Town caused by Great Wenchuan Earthquake, in: Geotechnical Risk and Safety, Taylor and Francis Group, London, 237-244, 2009.

Zhou, G. D.: The mechanisms of debris flow, PhD Thesis, Hong Kong University of Science and Technology, Hong Kong, 2010. 